\title{
Acetaminophen Removal from Water by Microalgae and Effluent Toxicity Assessment by the Zebrafish Embryo Bioassay
}

\author{
Carla Escapa ${ }^{1,2} \oplus$, Ricardo N. Coimbra ${ }^{3}$, Teresa Neuparth ${ }^{2} \oplus$, Tiago Torres ${ }^{2}$, \\ Miguel M. Santos ${ }^{2,4, *}$ and Marta Otero ${ }^{3,5, * \mathbb{D}}$ \\ 1 IMARENABIO-Institute of Environment, Natural Resources and Biodiversity, Department of Applied \\ Chemistry and Physics, Universidad de León, Av. Portugal s/n, 24071 León, Spain; carla.escapa@unileon.es \\ 2 CIMAR/CIIMAR-Interdisciplinary Centre of Marine and Environmental Research, Endocrine Disruptors and \\ Emerging Contaminants Group, University of Porto, Av. General Norton de Matos s/n, 4450-208 Matosinhos, \\ Portugal; tneuparth@ciimar.up.pt (T.N.); torres_tapt@hotmail.com (T.T.) \\ 3 Department of Environment and Planning, University of Aveiro, Campus Universitário de Santiago, \\ 3810-193 Aveiro, Portugal; ricardo.coimbra@ua.pt \\ 4 FCUP-Department of Biology, Faculty of Sciences, University of Porto, Rua do Campo Alegre, \\ 4169-007 Porto, Portugal \\ 5 CESAM-Centre for Environmental and Marine Studies, Campus Universitário de Santiago, \\ 3810-193 Aveiro, Portugal \\ * Correspondence: santos@ciimar.up.pt (M.M.S.); marta.otero@ua.pt (M.O.)
}

Received: 8 August 2019; Accepted: 12 September 2019; Published: 15 September 2019

\begin{abstract}
In this work, zebrafish embryo bioassays were performed to assess the efficiency of microalgae in the removal of acetaminophen from water. Chlorella sorokiniana (CS), Chlorella vulgaris (CV) and Scenedesmus obliquus (SO) were the strains used for water treatment. Toxic effects on zebrafish embryo caused by effluents from microalgae treatment were compared with those observed under exposure to experimental solutions with known concentrations of acetaminophen. The three microalgae strains allowed for the reduction of acetaminophen concentration and its toxic effects, but CS was the most efficient one. At the end of the batch culture, a $67 \%$ removal was provided by CS with a reduction of $62 \%$ in the total abnormalities on the exposed zebrafish embryo. On the other hand, toxic effects observed under exposure to effluents treated by microalgae were alike to those determined for acetaminophen experimental solutions with equivalent concentration. Thus, it may be inferred that microalgae biodegradation of acetaminophen did not involve an increased toxicity for zebrafish embryo.
\end{abstract}

Keywords: phyco-remediation; algae; wastewater; emerging contaminants; paracetamol; Danio rerio

\section{Introduction}

Pharmaceuticals belong to the class of emerging contaminants and, over the last decades, their presence and persistence in the environment has caused great concern due to the threat that they represent for aquatic and terrestrial life [1]. Wastewater is a main source of pharmaceuticals in the aquatic environment, a main difficulty in wastewater treatment being that these pollutants are single compounds with an individual behaviour and represent only a minor part of the wastewater organic load [2]. These singularities have called to new approaches in wastewater treatment to limit the discharge of pharmaceuticals in receiving waters [2].

On the other hand, the application of microalgae-based water treatments is raising scientific interest. Among others, advantages of microalgae treatment include photoautotrophic growth, relatively small amounts of operational inputs, eco-friendliness, $\mathrm{CO}_{2}$ sequestration, high-value by-products such as 
nutraceuticals and cosmetics and simultaneous production of low-value foodstuff for aquaculture. Moreover, algal biomass resulting from water treatment may be also used as biosorbent, fertilizer, animal feed, for energy valorisation or biofuels production [3-6]. Thus, integrating microalgae culture and wastewater treatment is a sustainable alternative that comprises energy and resources recovery [7].

Microalgae cultivation systems can be classified as open or closed, like photobioreactors (PBRs) [8]. The latter allow the guarantee of mono-cultures and a tighter control of operation conditions, their application for water treatment (with simultaneous $\mathrm{CO}_{2}$ sequestration) having been initiated at the Carnegie Institute of Washington in 1953 [9]. Since then, the study of microalgae for water treatment has been mainly focused on the removal of nutrients [9-12], although these systems have been also used for the removal of heavy metals $[9,11,12]$ and, more recently, pharmaceuticals $[6,9,11,12]$.

Despite the scale-up challenges that microalgae water treatment still faces, high removal percentages have been attained for most of target pharmaceuticals at laboratory scale [11,12]. In fact, it is well-known that micro-organisms such as bacteria, fungi, protozoa and microalgae tend to degrade organic contaminants to a much larger degree than humans and animals [13]. Microalgae removal of pharmaceuticals occur by bioaccumulation, bioadsorption and, especially, by biodegradation [6]. However, pharmaceuticals degradation may result in the generation of transformation products (TPs) that can be equally or even more toxic than parent compounds [14], which casts doubt on the convenience of using microalgae-based treatments in the removal of pharmaceuticals. Monitoring TPs from microalgae water treatment, which would dispel any doubts about this issue, is impractical. In fact, due to analytic limitations, few authors have attempted to determine TPs from microalgae biodegradation of pharmaceuticals and hormones [15-17]. Indeed, from a practical point of view, it is not realistic neither necessary to identify every possible TP for a given micropollutant [18].

In the literature, the evaluation of microalgae efficiency in the removal of pharmaceuticals is commonly expressed in percentage terms. Though this approach is used to assess the reduction of conventional pollutants in conventional water treatment plants, due to the possible generation of TPs, it is not conclusive in the case of micropollutants [18]. Given the unviability of full monitoring of TPs from the degradation of this sort of pollutants, complementing analytical measurements with toxicological data may be a suitable strategy for the evaluation of microalgae-based treatments efficiency. Furthermore, with ever-increasing environmental awareness, proving the capacity of microalgae-based treatments to reduce not only concentration, but also the associated toxicity effects of pharmaceuticals, would serve to encourage their practical implementation. Therefore, in this context, this work aimed at verifying if pharmaceutical removal by microalgae co-occurs with a reduction of toxicity effects.

Chlorella vulgaris, Chlorella sorokiniana and Scenedesmus obliquus, which are among the most commonly employed microalgae strains in water treatment, were used and compared in this work regarding their efficiency in the removal of acetaminophen and its toxic effects. Acetaminophen (paracetamol, acetyl-para-aminophenol, $\mathrm{N}$-acetyl-p-aminophenol) was selected as the target pharmaceutical, since it is a widely used over-the-counter analgesic and antipyretic drug. Due to its extensive consumption, this pharmaceutical is mostly ubiquitous in influents to sewage treatment plant (STPs) and appreciable concentrations have been found in STP effluents and surface waters [19]. Regarding the toxicity evaluation of effluents from microalgae treatment, zebrafish embryo bioassays were carried out in this work. Despite higher animals traditionally being considered models of excellence for the evaluation of drugs toxicity, zebrafish has recently been presented as a reliable vertebrate model to determine developmental toxicity and general toxicity of drugs [20]. Zebrafish (Danio rerio) embryos represent an attractive model for toxicity studies on pharmaceuticals [21] and hold several practical advantages, namely their small size, large robustness, short life-cycle, great number of offspring, simple cost-effective management and reproduction at laboratory-scale and translucent eggs that allow for stereomicroscope monitoring of embryo development [22,23]. 


\section{Material and Methods}

\subsection{Zebrafish (Danio rerio) Embryo Toxicity Bioassays}

\subsubsection{Fertilization and Collection of Zebrafish Embryos}

Zebrafish adults were kept in a 70-L aquaria filled with freshwater at $28 \pm 1{ }^{\circ} \mathrm{C}$ and under a $14: 10 \mathrm{~h}$ light:dark photoperiod, as described by Soares et al. [24]. Ad libitum feeding of these adults was done twice a day, the feedstuff consisting of Tetramin (Tetra, Melle, Germany) supplemented with Artemia spp.

For spawning, adult males and females (2:1) were placed in 30-L breeding tanks overnight under the same water conditions above described. Then, ovulation and fertilization of the eggs were stimulated by the beginning of light period [24]. Next, fertilized eggs were collected from the bottom of the tank and washed with water several times in order to remove detritus and avoid micro-organisms' proliferation during the subsequent bioassays [25].

\subsubsection{Experimental Solutions}

In order to validate the applicability of Danio rerio embryo bioassays for the targeted aim, these were first carried out on experimental solutions of acetaminophen with concentrations in the range of influent and effluent concentrations in microalgae treatments, as described in Section 2.2. For this purpose, acetaminophen $\left(\mathrm{C}_{8} \mathrm{H}_{9} \mathrm{NO}_{2}, \geq 99 \%\right)$ acquired from Sigma-Aldrich (Madrid, Spain) was used to make experimental solutions with the following concentrations: 25, 250, 2500, 6250, 12,500 and $25,000 \mu \mathrm{g} \mathrm{L}^{-1}$. These solutions were prepared by dilution of acetaminophen in the standard microalgae culture medium Mann and Myers [26] and freshwater (at 1:1 ratio). Furthermore, an experimental and a solvent control were also tested. For each acetaminophen concentration, experimental and solvent control, six replicates were carried out. All the solutions and controls were daily prepared in order to guarantee the pharmaceutical concentration and to avoid micro-organisms proliferation.

\subsubsection{Zebrafish Embryo Bioassays}

The static-water renewal toxicological zebrafish bioassays were carried out following the ecotoxicity test guidelines of the Organization for Economic Cooperation and Development (OECD), Test No. 236: Fish Embryo Acute Toxicity (FET) Test [27] and Ribeiro et al. [25]. After embryos observation using a magnifying glass, 10 fertilized eggs were selected and randomly allocated into 24-wells plates filled with $2 \mathrm{~mL}$ of freshly prepared acetaminophen solution, experimental control or solvent control. The 24-wells plates were then incubated at $26.5^{\circ} \mathrm{C}$ during $144 \mathrm{~h}$ and under the same photoperiod conditions as the zebrafish adults. The medium was renewed daily in order to maintain dissolved oxygen and acetaminophen nominal concentrations constant during the bioassay and to remove fungi or other organisms that could proliferate in the well.

The effects of exposure were assessed at four distinct periods described by Kimmel et al. [28] as representative of important steps of embryo development (embryo pictures at these periods are depicted in Figure S1): gastrula period (75\% epiboly stage), pharyngula period (prim15-16), larval stage (protruding-mouth) and juvenile, which were respectively observed at $8,32,80$ and $144 \mathrm{~h}$ post fertilization (hpf). At each observation time, non-viable embryos were removed if present, mortality rate was assessed and morphological abnormalities were rated as abnormalities in eyes, head, tail or yolk-sac, developmental delay, abnormal cells, pericardial oedema, opaque chorion, excess or lack of pigmentation, lateral position, reduced mobility and involuntary movements. The total abnormalities rate was recorded as the percentage of embryos with at least one of the referred abnormalities in comparison to the control. Also, $75 \%$ epiboly stage at $8 \mathrm{hpf}$, hatching rate at $80 \mathrm{hpf}$ and larval length at $144 \mathrm{hpf}$ were evaluated in accordance with FET 236 [27] and Torres et al. [23]. Observations were performed using an inverted microscope (Nikon Eclipse 5100T, Nikon Corporation, Tokyo, Japan) equipped with a digital camera (Nikon D5-Fi2, Nikon Corporation, Tokyo, Japan) and a microscope camera controller (Nikon's Digital Sight DS-U3, Nikon Corporation, Tokyo, Japan). 
In all sets of experiments, it was verified that the control groups did not show a mortality rate higher than $10 \%$, which ensures that zebrafish embryo bioassays were adequately carried out.

\subsubsection{Statistical Analysis}

Statistical analysis was performed with SPPS Statistics software (version 21.0) (International Business Machines Corporation (IBM), New York, NY, USA). Data were first tested for variance normality and homogeneity using Kolmogorov-Smirnov and Levene tests. If these assumptions were met, differences between treatments were tested for significance by means of one-way factorial ANOVA followed by Newman-Keuls multiple comparison test to compare the control groups and each of the exposed groups. If the homogeneity and normality were not met, data were analysed by the non-parametric Kruskal-Wallis test, followed by a multiple comparison rank test (U Mann-Whitney test). Results for mortality rate, morphological and developmental abnormalities were expressed as the mean \pm standard error (SE) and differences were considered significant for $p \leq 0.05$. Statistical analysis was done at each observation time defined at the previous section. Experimental and solvent controls were grouped when no significant differences between them were detected.

\subsection{Acetaminophen Removal from Water by Microalgae}

Microalgae used in this work for the removal of acetaminophen from water were Chlorella sorokiniana (CS), Chlorella vulgaris (CV) and Scenedesmus obliquus (SO). The selection of these strains was based on their well-established use for water treatment. The culture of these microalgae was carried out under identical conditions in bubbling column PBRs (diameter $=4 \mathrm{~cm}$, height $=30 \mathrm{~cm}$ ), which were operated under batch conditions and at constant temperature $\left(25 \pm 1^{\circ} \mathrm{C}\right)$, irradiance $\left(370 \mu \mathrm{E} \mathrm{m} \mathrm{m}^{-2} \mathrm{~s}^{-1}\right)$, photoperiod (12:12), aeration with $\mathrm{CO}_{2}$ enriched air $(0.3 \mathrm{v} / \mathrm{v} / \mathrm{min})$ and $\mathrm{pH}(7.5 \pm 0.5)$, as described in a previous work [29].

For each CS, CV and SO, PBRs were run in triplicate and simultaneously in order to evaluate the removal efficiency of acetaminophen. In these experiments, initial concentration of acetaminophen in the culture medium was $25,000 \mu \mathrm{g} \mathrm{L}^{-1}$. Such a relatively high feeding concentration was needed to guarantee the applicability of the methodologies employed in this work. Negative controls $(25,000 \mu \mathrm{g} \mathrm{L}-1$ acetaminophen in culture medium, with no microalgae) and positive controls (microalgae in culture medium, with no acetaminophen) were also simultaneously run. During operation, a 5-mL aliquot was daily taken from each PBR (experiment, negative or positive control) in order to determine the concentration of microalgae biomass $\left(C_{b}\right)$ and that of acetaminophen so to respectively monitor microalgae growing and removal of the target pharmaceutical.

\subsubsection{Analytic Methods and Instrumentation}

All aliquots were analysed for $C_{b}$ and acetaminophen concentration. $C_{b}$ was determined by optical density at $680 \mathrm{~nm}\left(O D_{680}\right)$ using a UV-visible spectrophotometer (BECKMAN DU640). Equation (1), which was established from preliminary experiments, was used for the calculation of $C_{b}$ :

$$
O D_{680}=5.1834 C_{b}+0.0128, R^{2}=0.9983
$$

Acetaminophen concentration was analysed in a Waters HPLC 600 equipped with a 2487 dual $\lambda$ absorbance detector. A Phenomenex Gemini-NX C18 column $(5 \mu \mathrm{m}, 250 \mathrm{~mm} \times 4.6 \mathrm{~mm})$ was used for the separation and the wavelength of detection was $246 \mathrm{~nm}$. Before analysis, and in order to obtain clear samples for chromatographic analysis, aliquots were twice centrifuged at $7500 \mathrm{rpm}$ for $10 \mathrm{~min}$ (SIGMA 2-16P centrifuge). The mobile phase consisted of acetonitrile/ultrapure water $(30: 70, \mathrm{v} / \mathrm{v})$, which was filtered through a Millipore membrane (pore size $=0.45 \mu \mathrm{m}$ ) and degasified (for $30 \mathrm{~min}$ ) before use. HPLC quality acetonitrile $\left(\mathrm{CH}_{3} \mathrm{CN}\right)$ was purchased from DBH Prolabo Chemicals and ultrapure water was produced by a Millipore System. 
2.2.2. Evaluation of Effluents Toxicity by the Zebrafish Embryo Bioassay.

When microalgae concluded the exponential growth phase, $75 \mathrm{~mL}$ of effluent were taken from each PBR, homogenized and twice centrifuged $(7500 \mathrm{rpm})$ during $10 \mathrm{~min}$ in order to obtain clear samples. Next, the resulting supernatant was diluted (1:1) with freshwater to be used in zebrafish embryo bioassays. Such a dilution was set as the most favourable on the basis of a preliminary study using different dilutions with freshwater $(1: 7,1: 3,1: 1,1: 0)$, which was carried out to determine an appropriate ratio that allowed for the observation of effects in zebrafish embryo but avoided biased effects caused by the culture medium. Still, for additional validation of the absence of biased effects, bioassays were also carried out using a 1:3 dilution with freshwater. Effluents from the microalgae treatment (at each 1:1 and 1:3 dilution ratios with freshwater) were tested for zebrafish embryo toxicity following the procedure already described in Section 2.1.

\section{Results}

\subsection{Acetaminophen Experimental Solutions}

Results on the mortality and total abnormalities of zebrafish embryos exposed to acetaminophen experimental solutions are shown in Figure 1 while the observed abnormalities are depicted in Table 1.
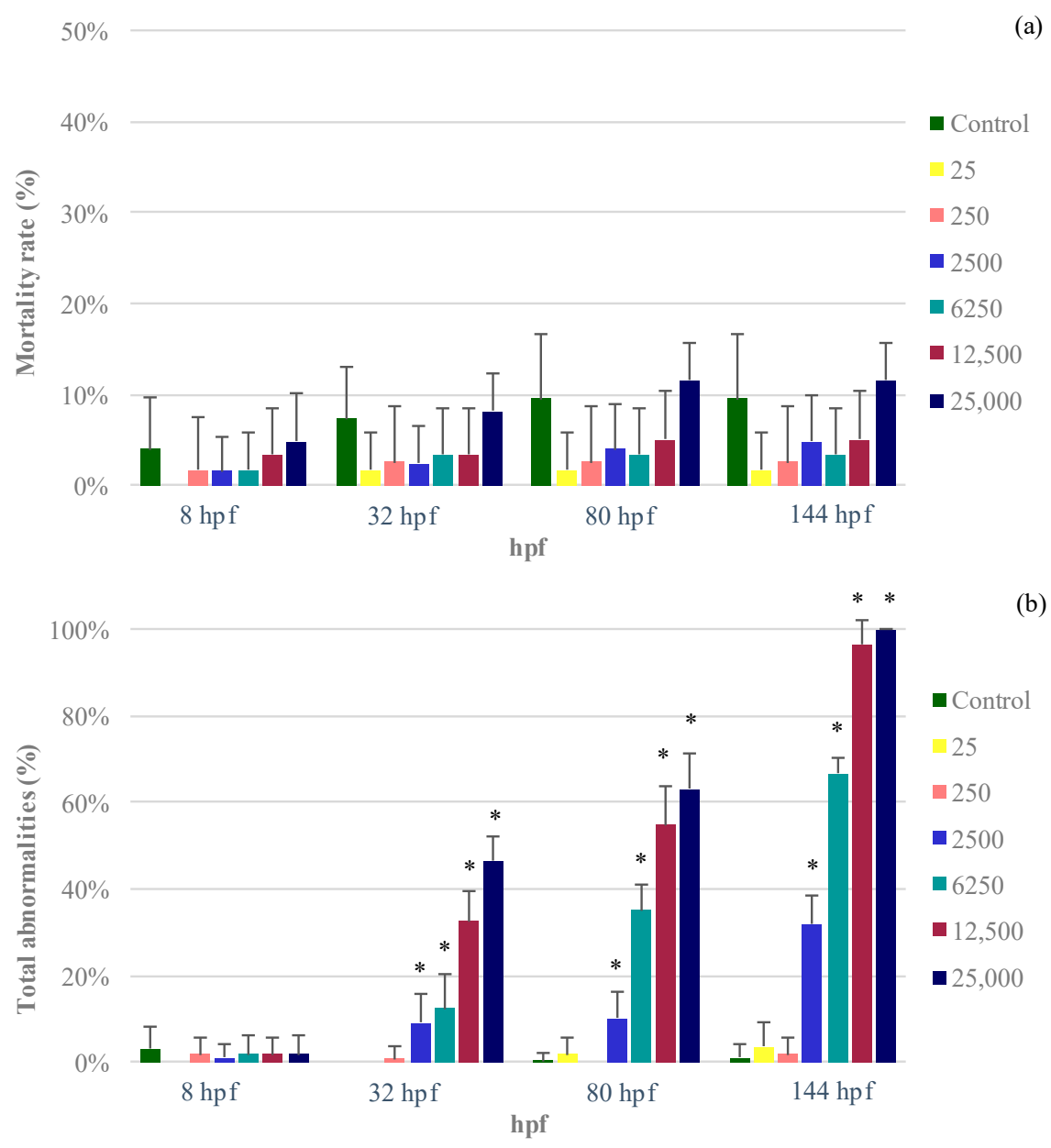

Figure 1. Mortality (a) and total abnormalities (b) observed for zebrafish embryos exposed to acetaminophen experimental solutions $\left(25,250,2500,6250,12,500\right.$ and 25,000 $\left.\mu \mathrm{g} \mathrm{L}^{-1}\right)$ at the different observation times $(8,32,80$ and $144 \mathrm{~h}$ post fertilization (hpf)). Note: Mean results ( $n=12$ for control; $n=6$ for exposed groups) are shown together with standard error (SE). Results significantly different from control $(p \leq 0.05)$ are marked with a symbol $\left(^{*}\right)$. 
Table 1. Effects of acetaminophen experimental solutions with different concentrations on zebrafish embryos at the observation time-points considered in this work.

\begin{tabular}{|c|c|c|c|c|c|c|c|c|}
\hline $\begin{array}{c}\text { Observation } \\
\text { Time }\end{array}$ & $\begin{array}{l}\text { Acetaminophen } \\
\text { Concentration }\end{array}$ & $\begin{array}{c}75 \% \text { Epiboly } \\
\text { Rate }\end{array}$ & $\begin{array}{c}\text { Developmental } \\
\text { Delay }\end{array}$ & $\begin{array}{c}\text { Lack of } \\
\text { Pigmentation }\end{array}$ & $\begin{array}{c}\text { Excess of } \\
\text { Pigmentation }\end{array}$ & Lateral Position & $\begin{array}{l}\text { Involuntary } \\
\text { Movements }\end{array}$ & $\begin{array}{c}\text { Larval Length } \\
(\mu \mathrm{m})\end{array}$ \\
\hline \multirow{7}{*}{$8 \mathrm{hpf}$} & 0 (control) & $93.7 \pm 7.6$ & $3.2 \pm 4.9$ & & & & & \\
\hline & 25 & $100 \pm 0.0$ & $0.0 \pm 0.0$ & & & & & \\
\hline & 250 & $97.5 \pm 6.2$ & $0.8 \pm 2.9$ & & & & & \\
\hline & 2500 & $96.8 \pm 6.4$ & $0.9 \pm 3.2$ & & & & & \\
\hline & 6250 & $96.5 \pm 5.5$ & $1.9 \pm 4.5$ & & & & & \\
\hline & 12,500 & $95.0 \pm 5.5$ & $0.0 \pm 0.0$ & & & & & \\
\hline & 25,000 & $93.5 \pm 8.1$ & $0.0 \pm 0.0$ & & & & & \\
\hline \multirow{7}{*}{$32 \mathrm{hpf}$} & 0 (control) & & $0.0 \pm 0.0$ & $0.0 \pm 0.0$ & $0.0 \pm 0.0$ & & & \\
\hline & 25 & & $0.0 \pm 0.0$ & $0.0 \pm 0.0$ & $0.0 \pm 0.0$ & & & \\
\hline & 250 & & $0.0 \pm 0.0$ & $0.0 \pm 0.0$ & $0.0 \pm 0.0$ & & & \\
\hline & 2500 & & $0.0 \pm 0.0$ & $9.2 \pm 6.7$ & $0.0 \pm 0.0$ & & & \\
\hline & 6250 & & $0.0 \pm 0.0$ & $12.4 \pm 8.0$ & $0.0 \pm 0.0$ & & & \\
\hline & 12,500 & & $0.0 \pm 0.0$ & $32.6 \pm 6.8$ & $0.0 \pm 0.0$ & & & \\
\hline & 25,000 & & $0.0 \pm 0.0$ & $46.5 \pm 5.5$ & $0.0 \pm 0.0$ & & & \\
\hline \multirow{7}{*}{$80 \mathrm{hpf}$} & 0 (control) & & $0.0 \pm 0.0$ & $0.0 \pm 0.0$ & $0.0 \pm 0.0$ & & & \\
\hline & 25 & & $0.0 \pm 0.0$ & $0.0 \pm 0.0$ & $0.0 \pm 0.0$ & & & \\
\hline & 250 & & $0.0 \pm 0.0$ & $0.0 \pm 0.0$ & $0.0 \pm 0.0$ & & & \\
\hline & 2500 & & $0.0 \pm 0.0$ & $0.0 \pm 0.0$ & $9.4 \pm 6.7$ & & & \\
\hline & 6250 & & $0.0 \pm 0.0$ & $0.0 \pm 0.0$ & $35.2 \pm 5.8$ & & & \\
\hline & 12,500 & & $0.0 \pm 0.0$ & $0.0 \pm 0.0$ & $54.6 \pm 9.1$ & & & \\
\hline & 25,000 & & $0.0 \pm 0.0$ & $0.0 \pm 0.0$ & $63.0 \pm 8.4$ & & & \\
\hline \multirow{7}{*}{$144 \mathrm{hpf}$} & 0 (control) & & $0.0 \pm 0.0$ & $0.0 \pm 0.0$ & $0.0 \pm 0.0$ & $0.7 \pm 2.8$ & $0.0 \pm 0.0$ & $3861.23 \pm 66.85$ \\
\hline & 25 & & $0.0 \pm 0.0$ & $0.0 \pm 0.0$ & $0.0 \pm 0.0$ & $1.9 \pm 4.5$ & $0.0 \pm 0.0$ & $3874.83 \pm 69.40$ \\
\hline & 250 & & $0.0 \pm 0.0$ & $0.0 \pm 0.0$ & $0.0 \pm 0.0$ & $1.7 \pm 3.9$ & $0.0 \pm 0.0$ & $3900.42 \pm 49.33$ \\
\hline & 2500 & & $0.0 \pm 0.0$ & $0.0 \pm 0.0$ & $31.9 \pm 6.7$ & $0.9 \pm 3.2$ & $0.0 \pm 0.0$ & $3909.25 \pm 68.96$ \\
\hline & 6250 & & $0.0 \pm 0.0$ & $0.0 \pm 0.0$ & $66.7 \pm 3.7$ & $22.8 \pm 7.9$ & $0.0 \pm 0.0$ & $3980.83 \pm 89.77$ \\
\hline & 12,500 & & $0.0 \pm 0.0$ & $0.0 \pm 0.0$ & $96.5 \pm 5.5$ & $64.8 \pm 5.8$ & $26.3 \pm 5.5$ & $4052.83 \pm 44.20$ \\
\hline & 25,000 & & $0.0 \pm 0.0$ & $0.0 \pm 0.0$ & $100 \pm 0.0$ & $61.2 \pm 5.0$ & $35.1 \pm 7.6$ & $4047.67 \pm 78.22$ \\
\hline
\end{tabular}

Note: Control and solvent control were grouped. In addition, the treatments with the same concentration from different sets of experiments (2500 and $\left.250 \mu \mathrm{g} \mathrm{L}^{-1}\right)$ were grouped. Mean results ( $n=12$ for control; $n=6$ acetaminophen exposed groups) are shown together with SE. Results significantly different from control ( $p \leq 0.05)$ are marked in bold. 
As seen in Figure 1a, mean mortality rates were not larger than $12 \%$ in any case. Furthermore, the concentrations of acetaminophen here considered did not cause effects on the mortality at any observation time-point. Regarding total abnormalities, Figure $1 \mathrm{~b}$ evidences that abnormalities were not observed until $32 \mathrm{hpf}$, their incidence significantly increasing at longer time-points. In any case, significance increases in total abnormalities were observed for acetaminophen initial concentrations higher than $250 \mu \mathrm{g} \mathrm{L}^{-1}$ at 32, 80 and $144 \mathrm{hpf}$.

Table 1 shows that the $75 \%$ epiboly rate and total abnormalities at $8 \mathrm{hpf}$ did not show significant differences at any acetaminophen concentration in comparison with the control. At $32 \mathrm{hpf}$, lack of pigmentation was observed in the embryos exposed to concentrations equal or higher than $2500 \mu \mathrm{g} \mathrm{L}^{-1}$ $(p \leq 0.05)$ in a range of $9.2 \%$ to $46.5 \%$. However, no developmental delay was detected. After $48 \mathrm{~h}$ $(80 \mathrm{hpf})$, abnormalities increased, and an excess of pigmentation was observed on larvae exposed to concentrations equal or higher than $2500 \mu \mathrm{g} \mathrm{L} \mathrm{L}^{-1}(p \leq 0.05)$, in a range of $10.2 \%$ to $63.0 \%$. Still, the hatching rate was not affected by any of the acetaminophen tested concentrations.

At $144 \mathrm{hpf}$, the effects of the pharmaceutical on total abnormalities increased significantly in comparison with control $(p \leq 0.05)\left(100 \%\right.$ in the case of $25,000 \mu \mathrm{g} \mathrm{L}^{-1}$ acetaminophen). Moreover, some of the larvae remained in lateral position. Indeed, those larvae exposed to the highest concentrations of acetaminophen that remained in lateral position, also showed spasms or involuntary movements (>35\% under 25,000 $\mu \mathrm{g} \mathrm{L}^{-1},>25 \%$ under 12,500 $\mu \mathrm{g} \mathrm{L}^{-1}$ ). Furthermore, the highest acetaminophen concentrations $\left(\geq 6250 \mu \mathrm{g} \mathrm{L}^{-1}\right)$ caused a marginal increase in the larvae length $(p>0.05)$.

Overall, the above results point towards time and concentration dependence of acetaminophen effects on zebrafish embryo. Yet, effects on mortality rate were not registered under exposure to any of the considered acetaminophen concentrations.

\subsection{Acetaminophen Removal from Water by Microalgae}

For the strains here considered, results on the concentration of acetaminophen in PBRs and microalgae biomass throughout the batch culture are shown in Figure 2. Acetaminophen concentration was observed to decrease while microalgae biomass increased during the culture of the three strains used in this work. The steady state was reached after eight or nine days of cultivation. During the culture, the concentration of acetaminophen in the negative controls was stable. Therefore, it may be stated that, in the treatment experiments, the decrease of acetaminophen concentration was associated to the presence of microalgae.

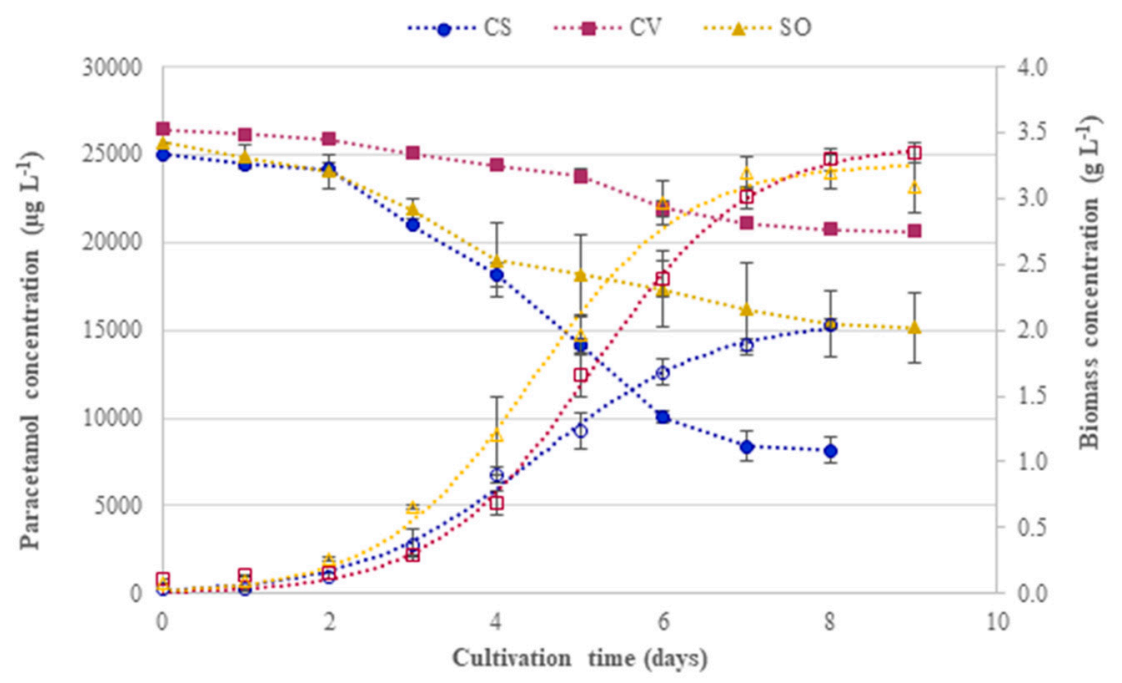

Figure 2. Concentration of acetaminophen (full symbols) and microalgae biomass (open symbols) in photobioreactors (PBRs) during the culture of Chlorella sorokiniana (CS), Chlorella vulgaris (CV) and Scenedesmus obliquus (SO). Note: Mean results $(n=3)$ are shown together with the corresponding SE. 
As may be seen in Figure 2, the removal of acetaminophen by CS, with outlet concentrations of about $8200 \mu \mathrm{g} \mathrm{L}^{-1}$, was more effective than that by $\mathrm{SO}$ or $\mathrm{CV}$, which provided final acetaminophen concentrations around 15,200 and $20,700 \mu \mathrm{g} \mathrm{L}^{-1}$, respectively. As for these concentrations in the effluents, the removal of acetaminophen at the end of the batch culture was $67 \%$ (CS), 39\% (SO) and $17 \%(\mathrm{CV})$. Strain specific differences must be underneath these different efficiencies, which are not directly related with biomass growth, since the biomass of CS at the end of the batch $\left(2 \mathrm{~g} \mathrm{~L}^{-1}\right)$ was lower than for SO and CV (about $3 \mathrm{~g} \mathrm{~L}^{-1}$ ).

\subsection{Evaluation of Effluents Toxicity by the Zebrafish Embryo Bioassay}

Mortality and total abnormalities in zebrafish embryo exposed to treated effluents by CS, CV and $\mathrm{SO}$ are shown in Figure 3. Additionally, abnormalities and larval length registered at each observation time-point are specified in Table 2. Furthermore, the observed effects associated to exposure to effluents at 1:3 dilution are shown within the Supplementary Material (Table S1).

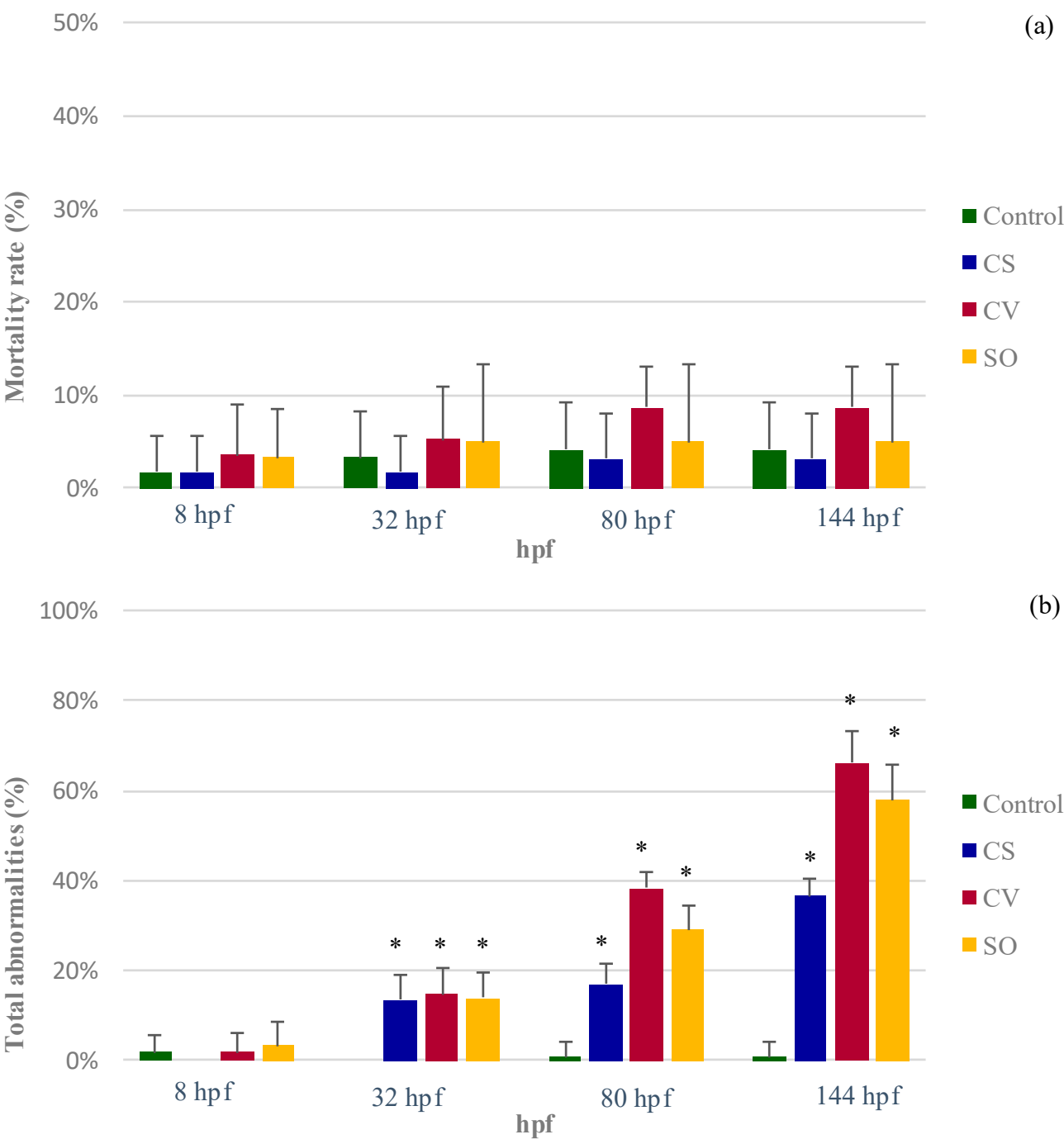

Figure 3. Mortality (a) and total abnormalities (b) observed for zebrafish embryos exposed to effluents from microalgae treatment for the removal of acetaminophen from water. Results are shown at the different observation times $(8,32,80$ and $144 \mathrm{hpf})$ for CS, CV and SO microalgae treatment. Note: Mean results ( $n=12$ for control; $n=6$ for exposed groups) are shown together with SE. Results significantly different from control $(p \leq 0.05)$ are marked with a symbol $(*)$. In Figure $3 a$, the scale of the vertical axis was fitted (from $0 \%$ to $50 \%$ ) for the visualization of results. 
Table 2. Effects of exposure to microalgae treated effluents on zebrafish embryos exposed to treated effluents by CS, CV and SO embryos at the observation time-points considered in this work.

\begin{tabular}{|c|c|c|c|c|c|c|c|c|}
\hline $\begin{array}{c}\text { Observation } \\
\text { Time }\end{array}$ & Effluent & $\begin{array}{c}75 \% \text { Epiboly } \\
\text { Rate }\end{array}$ & $\begin{array}{c}\text { Developmental } \\
\text { Delay }\end{array}$ & $\begin{array}{c}\text { Lack of } \\
\text { Pigmentation }\end{array}$ & $\begin{array}{c}\text { Excess of } \\
\text { Pigmentation }\end{array}$ & Lateral Position & $\begin{array}{l}\text { Involuntary } \\
\text { Movements }\end{array}$ & $\begin{array}{c}\text { Larval Length } \\
(\mu \mathrm{m})\end{array}$ \\
\hline \multirow{4}{*}{$8 \mathrm{hpf}$} & Control & $96.6 \pm 5.1$ & $1.8 \pm 4.1$ & & & & & \\
\hline & CS & $98.3 \pm 4.1$ & $0.0 \pm 0.0$ & & & & & \\
\hline & $\mathrm{CV}$ & $94.6 \pm 5.9$ & $1.9 \pm 4.5$ & & & & & \\
\hline & $\mathrm{SO}$ & $95.0 \pm 5.5$ & $3.3 \pm 5.2$ & & & & & \\
\hline \multirow{4}{*}{$32 \mathrm{hpf}$} & Control & & $0.0 \pm 0.0$ & $0.0 \pm 0.0$ & $0.0 \pm 0.0$ & & & \\
\hline & CS & & $0.0 \pm 0.0$ & $13.6 \pm 5.3$ & $0.0 \pm 0.0$ & & & \\
\hline & $\mathrm{CV}$ & & $0.0 \pm 0.0$ & $14.9 \pm 5.8$ & $0.0 \pm 0.0$ & & & \\
\hline & $\mathrm{SO}$ & & $0.0 \pm 0.0$ & $14.5 \pm 5.2$ & $0.0 \pm 0.0$ & & & \\
\hline \multirow{4}{*}{$80 \mathrm{hpf}$} & Control & & $0.0 \pm 0.0$ & $0.0 \pm 0.0$ & $0.0 \pm 0.0$ & & & \\
\hline & CS & & $0.0 \pm 0.0$ & $0.0 \pm 0.0$ & $17.0 \pm 4.6$ & & & \\
\hline & $\mathrm{CV}$ & & $0.0 \pm 0.0$ & $0.0 \pm 0.0$ & $36.5 \pm 2.7$ & & & \\
\hline & $\mathrm{SO}$ & & $0.0 \pm 0.0$ & $0.0 \pm 0.0$ & $25.2 \pm 8.4$ & & & \\
\hline \multirow{4}{*}{$144 \mathrm{hpf}$} & Control & & $0.0 \pm 0.0$ & $0.0 \pm 0.0$ & $0.0 \pm 0.0$ & $0.0 \pm 0.0$ & $0.0 \pm 0.0$ & $3856.88 \pm 45.84$ \\
\hline & CS & & $0.0 \pm 0.0$ & $0.0 \pm 0.0$ & $36.7 \pm 3.7$ & $0.0 \pm 0.0$ & $0.0 \pm 0.0$ & $3862.85 \pm 54.11$ \\
\hline & $\mathrm{CV}$ & & $0.0 \pm 0.0$ & $0.0 \pm 0.0$ & $64.6 \pm 9.4$ & $32.1 \pm 6.2$ & $0.0 \pm 0.0$ & $4067.03 \pm 35.16$ \\
\hline & $\mathrm{SO}$ & & $0.0 \pm 0.0$ & $0.0 \pm 0.0$ & $54.2 \pm 8.1$ & $22.9 \pm 6.7$ & $0.0 \pm 0.0$ & $4027.35 \pm 42.54$ \\
\hline
\end{tabular}

Note: Control and solvent control were grouped. Significant differences from control $(p \leq 0.05)$ are marked in bold. Data are expressed as mean \pm SE $(n=12$ for control; $n=6$ for effluents exposed groups). 
As already observed for the acetaminophen experimental solutions (Figure 1a), no significant effects on mortality were either observed on zebrafish embryo after exposure to effluents from microalgae treatment (Figure 3a). With respect to total abnormalities incidence (Figure 3b), no differences with the control were observed for effluents at $8 \mathrm{hpf}$. However, at $32 \mathrm{hpf}$ and longer time-points, exposure to effluents from microalgae treatment caused a significant increase of the percentage of total abnormalities in zebrafish embryo as compared with the control. Still, differences among the three microalgae strains were just revealed at $80 \mathrm{hpf}$ and at $144 \mathrm{hpf}$, being higher at $144 \mathrm{hpf}$. In this regard, the average percentages of total abnormalities caused by effluents from CS, SO and CV at $144 \mathrm{hpf}$ were $37 \%$, $66 \%$ and $58 \%$, respectively. These values are all comprised between the percentages determined for acetaminophen experimental solutions of 2500 and $6250 \mu \mathrm{g} \mathrm{L}^{-1}$ (Figure $1 \mathrm{~b}$ ) and evidence that microalgae treatment led to a reduction of total abnormalities incidence as compared with that observed for the initial concentration of acetaminophen $(12,500 \mu \mathrm{g} \mathrm{L}-1$ in Figure $1 \mathrm{~b}$, as for the 1:1 dilution). On the other hand, the percentages of total abnormalities caused by exposure to effluents (Figure 3b) were parallel with the efficiency of each microalgae strain in the removal of acetaminophen, which was referred in the previous section $(67 \%(\mathrm{CS}), 39 \%(\mathrm{SO})$ and $17 \%(\mathrm{CV}))$.

Concerning the anomalies caused in zebrafish embryo by the effluents from microalgae treatment, Table 2 shows that neither the $75 \%$ epiboly rate at $8 \mathrm{hpf}$ nor the hatching rate at $80 \mathrm{hpf}$ were altered in comparison to the control. Moreover, at $32 \mathrm{hpf}$ a significant $(p \leq 0.05)$ lack of pigmentation on embryos exposed to effluents was observed, with average incidence below $15 \%$ for the three microalgae treatments. At $80 \mathrm{hpf}$, the incidence of total abnormalities in embryos exposed to effluents increased (Figure $3 b$ ), although these abnormalities were exclusively excess of pigmentation (Table 2). Effluents from CV and SO showed higher mean of abnormalities ( $36 \%$ and $25 \%$, respectively) than effluents from CS (17\%). Still, it was at $144 \mathrm{hpf}$ when effects of effluents on zebrafish embryos were more visible, which reflects the time dependence of effects that was already observed for acetaminophen experimental solutions.

As seen in Table 2, at $144 \mathrm{hpf}$, exposure to effluents from the three microalgae treatments caused an excess of pigmentation, which ranged from $37 \%$ (CS) to $65 \%$ (CV). In addition, embryo exposed to effluents from CV and SO remained in lateral position (mean incidence of $32 \%$ and $23 \%$, respectively) and showed larger larval length. Therefore, the incidence of effects on zebrafish embryos has a parallelism with the final concentration of acetaminophen at the end of the culture, as shown in Figure $2(\mathrm{CV}>\mathrm{SO}>\mathrm{CS})$. This is further corroborated by the results obtained under the 1:3 dilution here considered (Table S1), evidencing that the larger the acetaminophen concentration in the effluent, the larger the incidence of effects on zebrafish embryos.

\section{Discussion}

Acetaminophen experimental solutions tested in this work (25 to $25,000 \mu \mathrm{g} \mathrm{L}^{-1}$ ) did not affect the mortality of exposed zebrafish embryo at any of the developmental stages considered. Coincidently with these results, no significant effects on mortality were noticed by Nogueira et al. [30] on zebrafish embryo subjected 5 to $3125 \mu \mathrm{g} \mathrm{L}{ }^{-1}$ acetaminophen up to $96 \mathrm{hpf}$. Under a narrower exposure concentration ( 5 to $500 \mu \mathrm{g} \mathrm{L}^{-1}$ acetaminophen in $0.005 \%$ dimethyl sulphoxide (DMSO)) and with observation times until $96 \mathrm{hpf}$, Xia et al. [31] also did not observe an increase in the mortality rate of zebrafish embryo. Likewise, but at higher concentrations (151 to 756,000 $\left.\mu \mathrm{g} \mathrm{L}^{-1}\right)$, Pandya et al. [32] did not detect mortality effects in zebrafish embryos exposed to acetaminophen solutions in experiments with a duration of five days post-fertilization (dpf). Similarly, Peng et al. [33], using a transgenic zebrafish line Tg (wt1b: GFP) for the study of nephrotoxicity, observed no effects (12-72 hpf) on the survival of embryos exposed to even higher concentrations of acetaminophen (340, 3400 and $\left.6804 \mathrm{mg} \mathrm{L}^{-1}\right)$. Contrarily, under lower concentrations $\left(1,5,10,50\right.$ and $100 \mu \mathrm{g} \mathrm{L}^{-1}$ acetaminophen dissolved in $0.1 \%$ aqueous ethanol), David and Pancharatna [34] observed significantly increased mortality rates for concentrations equal or higher than $5 \mu \mathrm{g} \mathrm{L} \mathrm{L}^{-1}$. 
In the present study, under acetaminophen exposure, embryo abnormalities were registered in zebrafish for concentrations equal or higher than $2500 \mu \mathrm{g} \mathrm{L}^{-1}$ at observation time-points equal or longer than $32 \mathrm{hpf}$. These abnormalities were lack of pigmentation at $32 \mathrm{hpf}$, excess of pigmentation at $80 \mathrm{hpf}$, and, at $144 \mathrm{hpf}$, excess of pigmentation, lateral position, involuntary movements and larger larval length. Furthermore, the incidence of abnormalities increased with observation time and concentration. Likewise, no effects were observed on zebrafish embryo by Nogueira et al. [30] after the first $24 \mathrm{~h}$ of exposure to 5 to $3125 \mu \mathrm{g} \mathrm{L} \mathrm{L}^{-1}$ acetaminophen. However, although the dose-response was not so clear as in this work, at $48 \mathrm{hpf}$ and longer observation times, abnormalities were noticed for the embryos and larvae exposed to acetaminophen, namely lack of pigmentation (48 and $72 \mathrm{hpf}$ ), abnormal bending of the spine (72 and $96 \mathrm{hpf}$ ) and alteration of the larvae equilibrium (72 hpf) [30]. David and Pancharatna [34] also observed that the distribution of pigment in zebrafish embryo was dose-dependent, detecting a lack of pigmentation under 50 and $100 \mu \mathrm{g} \mathrm{L}{ }^{-1}$ acetaminophen. Moreover, these authors [34] found that larvae exposed to 10, 50 and $100 \mu \mathrm{g} \mathrm{L}^{-1}$ acetaminophen showed altered swimming behaviour such as vibratory/shivering. Differently, Xia et al. [31] did not observe significant impacts on zebrafish embryo movement from acetaminophen exposure to 5,50 and $500 \mu \mathrm{g} \mathrm{L}^{-1}$. The latter study is in agreement with observations in this work, since involuntary movements occurred just for embryos exposed to the highest acetaminophen concentrations, namely 12,500 and $25,000 \mu \mathrm{g} \mathrm{L}{ }^{-1}$.

During microalgae cultivation in PBRs for water treatment, CS was clearly the most effective in removing acetaminophen, as compared with $\mathrm{SO}$ and, especially, CV. CS was also more efficient than SO and $\mathrm{CV}$ in the removal of salicylic acid [35]. However, in the case of diclofenac, $\mathrm{SO}$ was most capable than CS and CV [36], which evidences the importance of strain assortment for optimizing microalgae removal of specific pharmaceuticals from water. Zebrafish embryo exposure to the effluents from microalgae treatment further confirmed differences between strains. Although mortality rate was not affected by exposition to effluents, effects on the percentage of abnormalities was strain dependent. The effects were more remarkable in the sense $\mathrm{CV}>\mathrm{SO}>\mathrm{CS}$, that is, contrary to the efficiency in the removal of acetaminophen. On the other hand, the reduction of acetaminophen toxic effects by treatment with these strains was also evaluated in this study. For this purpose, effluents from microalgae treatment were diluted at 1:1 with freshwater so to prevent the culture medium masking effects on embryo. Hence, comparing results in Figure 3 and Table 2 with those observed for 12,500 $\mu \mathrm{g} \mathrm{L}{ }^{-1}$ acetaminophen (Figure 1 and Table 1), it was clear that microalgae treatment by CS, CV and SO provided a reduction of effects on zebrafish embryo. This reduction was not evident for the shorter observation time-points ( 8 and $32 \mathrm{hpf}$ ) but was patent at 80 and $144 \mathrm{hpf}$. At the latter time-points, total abnormalities caused by exposure to the experimental solution of acetaminophen $\left(12,500 \mu \mathrm{g} \mathrm{L}^{-1}\right)$ were $55 \%$ and $97 \%$, respectively. Also, as can be observed in Table 1, the acetaminophen concentration of $12,500 \mu \mathrm{g}$ $\mathrm{L}^{-1}$ caused excess of pigmentation in the $97 \%$ of the larvae at $144 \mathrm{hpf}$. Moreover, $65 \%$ remained in lateral position, $26 \%$ also showed spasms or involuntary movements and larvae were significantly larger than the control. In comparison, exposure to effluents from CS, which was the most capable in removing acetaminophen (67\%, as shown in Figure 2), caused $17 \%$ and $37 \%$ of total abnormalities at 80 and $144 \mathrm{hpf}$, respectively, these being just restricted to lack of pigmentation. Meanwhile, for effluents from CV treatment, which was the least efficient, the average total abnormalities were $38 \%$ ( $80 \mathrm{hpf})$ and $63 \%$ (144 hpf), abnormalities including lack of pigmentation (32 hpf), excess of pigmentation (80 and $144 \mathrm{hpf})$, lateral position (144 hpf) and larval length (144 hpf). It is important to highlight that toxic effects on the embryo caused by exposure to microalgae-treated effluents were equivalent to those observed by acetaminophen experimental solutions with equivalent concentration. For instance, under exposure to the effluent from $\mathrm{CV}$ treatment $\left(10,326 \mu \mathrm{g} \mathrm{L}^{-1}\right.$ acetaminophen, at 1:1 dilution) the total abnormalities at $144 \mathrm{hpf}$ were $63 \%$ (Figure 3), which was slightly lower than the abnormalities observed for the acetaminophen solution of $6250 \mu \mathrm{g} \mathrm{L}^{-1}$ (67\% at $144 \mathrm{hpf}$, Figure 1). Among the different mechanisms that may be under the removal of pharmaceuticals by microalgae, biodegradation has been pointed as the most relevant [6]. Contrarily to physical treatments such as adsorption-based treatments, which also make possible the recuperation of the removed pharmaceuticals [37], those 
treatments involving their degradation result in the generation of TPs. Indeed, the possibility of these TPs being even more toxic than the original compounds raises some controversy around the application of degradation treatments for the removal of pharmaceuticals from water. The generation of TPs from microalgae removal of acetaminophen was not assessed in this work. Nonetheless, according to the obtained results, the reduction of acetaminophen concentration by microalgae occurred together with a proportional decrease of toxic effects on zebrafish embryo exposed to effluents. Therefore, if TPs were produced during treatment, their toxicity and/or concentration did not mean an increased toxicity for this model. Still, it remains unknown if the reduction of toxicity occurred in parallel with the decrease of acetaminophen concentration since these results refer just to the end of microalgae batch cultivation. Indeed, as highlighted by Vo et al. [9], different intermediates and/or end products may be formed depending on the degradation mechanism and pathway. In this sense, Zhou et al. [38] found that the maximum accumulated concentration of 1,4-benzoquinone, which is the main TP formed during the microbial transformation of acetaminophen in natural waters, occurred at different reaction times among the different water samples.

In the literature, there is a lack of works on the comprehensive evaluation of microalgae removal of pharmaceuticals, namely by coupling toxicity and analytic assessments. To our best knowledge, except for our previous study regarding the removal of diclofenac [39] there are no published works using toxicity tests on fish for this purpose. Compared with diclofenac removal by microalgae (67\% to 99\%) [39], the removal of acetaminophen was less efficient (17\% to $67 \%)$. Still, in this work, the efficiency of CS in the removal of acetaminophen $(67 \%)$ was the same than that previously found for diclofenac [39]. The lower removal of acetaminophen by microalgae as compared with other pharmaceuticals, including diclofenac, was also observed by Villar-Navarro et al. [40]. These authors [40] observed that the efficiency of a high rate algal pond (HRAP) removing pharmaceuticals was comparable to that of an activated-sludge based conventional process, except for acetaminophen and ibuprofen, which were less efficiently removed in the HRAP. However, the higher efficiency removing nutrients was highlighted as an advantage of HRAPs for their use as an alternative (or addition as tertiary treatment) to more conventional approaches based on activated sludge [40].

The necessity of complementing analytical information on the percent removal of pharmaceuticals in order to evaluate treatment efficiency has already been pointed out by some authors. Several approaches taken in this sense for the specific case of acetaminophen are shown in Table 3. Measuring oxygen uptake by bacteria in activated sludge was the strategy used by Ali et al. [41] to complement information based on chemical analysis on the removal of pharmaceuticals (including acetaminophen) by biosorption onto modified dead biomass of SO. These authors observed a drastic decrease of dissolved oxygen by $91 \%$ and $95 \%$ for wastewaters containing a pharmaceutical mixture of $125 \mathrm{mg} / \mathrm{L}$ and $250 \mathrm{mg} / \mathrm{L}$, respectively. However, after the biosorption treatment, such wastewaters did not show significant differences from the control regarding the dissolved oxygen, which further proved the effectiveness of the treatment.

Although not for a microalgae-based treatment, but for the visible-light-driven photocatalytic removal of acetaminophen, Czech et al. [42] followed an analogous approach to that in this work and used Vibrio fischeri to assess the efficiency of the treatment for reducing water toxicity. These authors [42] concluded that photocatalytically treated model water containing acetaminophen revealed no toxicity to Vibrio fischeri. Similarly, Le et al. [43] coupled ecotoxicity (Vibrio fischeri $81.9 \%$, Microtox®screening tests) and chemical analysis monitoring during the electro-fenton oxidation of acetaminophen thus establishing a very useful relationship between the degradation pathway of acetaminophen and the global toxicity evolution of the solution.

The application of microalgae cultures for the uptake of pharmaceuticals from water has been studied by several authors, mainly in the last decade. Coincidently with results in this work, Xiong et al. [44] found that different microalgae strains differed in their efficiency to remove a target pharmaceutical (enrofloxacin). Furthermore, these authors observed that the consortium of these strains displayed a comparable removal capacity to that of the most effective species. Even when microalgae are present as 
consortia in the aquatic environment, available data on the arrangement of efficient microalgae consortia to remove several distinct pharmaceuticals from different therapeutic classes are rather limited.

Table 3. Published approaches to evaluate treatment efficiency in the removal of acetaminophen by complementing analytic information by toxicity assessments.

\begin{tabular}{|c|c|c|c|c|c|}
\hline Pharmaceutical/s & $\begin{array}{c}\text { Initial } \\
\text { Concentration } \\
\left(\mu \mathrm{g} \mathrm{L}^{-1}\right)\end{array}$ & Treatment & $\begin{array}{l}\text { Maximum } \\
\text { Percent } \\
\text { Removal }\end{array}$ & $\begin{array}{c}\text { Toxicity } \\
\text { Assessment }\end{array}$ & Reference \\
\hline $\begin{array}{c}\text { Mixture } \\
\text { (tramadol, } \\
\text { cefadroxil, } \\
\text { acetaminophen, } \\
\text { ciprofloxacin } \\
\text { and ibuprofen) }\end{array}$ & $\begin{array}{c}125 \times 10^{3}-250 \\
\times 10^{3} \text { (global } \\
\text { concentration } \\
\text { of the mixture) }\end{array}$ & $\begin{array}{c}\text { Biosorption onto } \\
\text { modified dead } \\
\text { microalgae biomass }\end{array}$ & - & $\begin{array}{l}\text { Oxygen uptake } \\
\text { by bacteria in } \\
\text { activated } \\
\text { sludge }\end{array}$ & [41] \\
\hline Acetaminophen & $10 \times 10^{3}$ & $\begin{array}{c}\text { Visible-light-driven } \\
\text { photocatalysis }\end{array}$ & $82 \%$ & Vibrio fischeri & [42] \\
\hline Acetaminophen & $151 \times 10^{3}$ & $\begin{array}{c}\text { Electro-fenton } \\
\text { oxidation }\end{array}$ & $\begin{array}{c}87 \% \\
\text { (mineralization) }\end{array}$ & Vibrio fischeri & [43] \\
\hline Acetaminophen & $25 \times 10^{3}$ & Microalgae removal & $67 \%$ & $\begin{array}{c}\text { Zebrafish } \\
\text { embryo }\end{array}$ & this work \\
\hline
\end{tabular}

Hydroxylation, side chain breakdown and ring cleavage have been reported as pathways for the biodegradation of aromatic pollutants by microalgae [45]. Nevertheless, more in-depth analyses need to be performed in order to explain differences between microalgae strains in the removal of specific pharmaceuticals. Furthermore, in view of the optimization of treatment duration, further studies should be done on the analysis of TPs and toxic effects throughout microalgae culture considering a broad spectrum of pharmaceuticals and strains. Finally, carrying out research on microalgae efficiency in the removal of pharmaceuticals using real wastewater matrices is a challenge to overcome in the near future.

\section{Conclusions}

In the considered range of concentrations (25 to $25,000 \mu \mathrm{g} \mathrm{L}^{-1}$ ), experimental solutions of acetaminophen did not cause effects on the mortality of zebrafish embryos but significantly increased the total abnormalities at acetaminophen concentrations $\geq 2500 \mu \mathrm{g} \mathrm{L}^{-1}$. Microalgae-based treatments by CS, CV and SO presented different efficiencies in the uptake of acetaminophen from water (17\% to $67 \%$ at the end of the batch cultivation). Chemical analyses were coupled to zebrafish embryo bioassays for assessing the efficiency of these strains to remove the target pharmaceutical. It was evidenced that CS was the most efficient strain in reducing both acetaminophen concentration and toxic effects on zebrafish embryo. Furthermore, results confirmed that the effects of effluents from microalgae treatment were alike to those determined for experimental solutions with equivalent acetaminophen concentrations. It can be therefore concluded that microalgae removal of acetaminophen occurred together with a reduction of toxicity to zebrafish embryo, further supporting the potential application of microalgae for the removal of pharmaceuticals from water.

Supplementary Materials: The following are available online at http://www.mdpi.com/2073-4441/11/9/1929/s1, Figure S1: Periods of the embryo development of Danio rerio: $(\mathrm{a}, \mathrm{b})$ gastrula period; $(\mathrm{c}, \mathrm{d})$ pharyngula period; $(\mathrm{e}, \mathrm{f})$ larval stage. Note: Sketches have been taken from Kimmel et al. [28] and pictures from microscope. Table S1: Effects on zebrafish embryo exposed to effluents from microalgae treatments at a 1:3 dilution with freshwater. Note: Mean results ( $n=12$ for control; $n=6$ for exposed groups) are shown together with SE. Results significantly different from control $(p \leq 0.05)$ are in bold.

Author Contributions: Conceptualization, M.O. and M.M.S.; experimental design, M.M.S., C.E. and M.O.; methodology, M.M.S.; experimentation, C.E.; experimental support, T.T., T.N. and M.M.S.; analytic support, 
R.N.C. and M.O.; resources, M.M.S.; data analysis and discussion, C.E., M.O. and M.M.S..; writing-original draft preparation, C.E., R.N.C. and M.O.; writing-review and editing, M.M.S., T.N. and M.O.

Funding: This research received funding by Fundação para a Ciência e a Tecnologia (FCT, Lisboa, Portugal), grant number IF/00314/2015. C.E. was supported by the Ministerio de Educación, Cultura y Deportes (Madrid, Spain), which awarded her with a grant for a short stay (EST15/00405) to be carried out at the Interdisciplinary Centre of Marine and Environmental Research (CIIMAR). T.N. was supported by the Fundação para a Ciência e a Tecnologia (FCT, Lisboa, Portugal), fellowship number SFRH/BPD/77912/2011. M.M.S. acknowledges funding from the project NOR-WATER “Poluentes emergentes nas águas da Galiza-Norte de Portugal: novas ferramentas para gestão de risco" (Reference: 0725_NOR_WATER_1_P), financed by "Programa de Cooperação Interreg Portugal/Espanha" (POCTEP) 2014-2020.

Acknowledgments: Thanks are due for financial support to Centre for Environmental and Marine Studies (CESAM) (UID/AMB/50017/2019), to FCT/MEC through national funds, and the co-funding by the European Regional Development Fund (FEDER), within the PT2020 Partnership Agreement and Compete 2020.

Conflicts of Interest: The authors declare no conflict of interest and that funders had no role in the design of the study; in the collection, analyses, or interpretation of data; in the writing of the manuscript, and in the decision to publish the results.

\section{References}

1. Quesada, H.B.; Baptista, A.T.A.; Cusioli, L.F.; Seibert, D.; Bezerra, C.D.O.; Bergamasco, R. Surface water pollution by pharmaceuticals and an alternative of removal by low-cost adsorbents: A review. Chemosphere 2019, 222, 766-780. [CrossRef] [PubMed]

2. Larsen, T.A.; Lienert, J.; Joss, A.; Siegrist, H. How to avoid pharmaceuticals in the aquatic environment. J. Biotechnol. 2004, 113, 295-304. [CrossRef] [PubMed]

3. Escapa, C.; Coimbra, R.N.; Nuevo, C.; Vega, S.; Paniagua, S.; García, A.I.; Calvo, L.F.; Otero, M. Valorization of Microalgae Biomass by Its Use for the Removal of Paracetamol from Contaminated Water. Water 2017, 9 , 312. [CrossRef]

4. Kim, J.-Y.; Kim, H.-W. Photoautotrophic Microalgae Screening for Tertiary Treatment of Livestock Wastewater and Bioresource Recovery. Water 2017, 9, 192. [CrossRef]

5. Coimbra, R.N.; Escapa, C.; Vázquez, N.C.; Noriega-Hevia, G.; Otero, M. Utilization of Non-Living Microalgae Biomass from Two Different Strains for the Adsorptive Removal of Diclofenac from Water. Water 2018, 10, 1401. [CrossRef]

6. Xiong, J.-Q.; Kurade, M.B.; Jeon, B.-H. Can Microalgae Remove Pharmaceutical Contaminants from Water? Trends Biotechnol. 2018, 36, 30-44. [CrossRef] [PubMed]

7. Coimbra, R.N.; Escapa, C.; Otero, M. Comparative Thermogravimetric Assessment on the Combustion of Coal, Microalgae Biomass and Their Blend. Energies 2019, 12, 2962. [CrossRef]

8. Acién, F.G.; Molina, E.; Reis, A.; Torzillo, G.; Zittelli, G.C.; Sepúlveda, C.; Masojídek, J. Photobioreactors for the production of microalgae. In Microalgae-based Biofuels and Bioproducts: From Feedstock Cultivation to End-Products; González-Fernández, C., Muñoz, R., Eds.; Woodhead Publishing Series in Energy: Cambridge, UK, 2018; pp. 1-44.

9. Vo, H.N.P.; Ngo, H.H.; Guo, W.; Nguyen, T.M.H.; Liu, Y.; Liu, Y.; Nguyen, D.D.; Chang, S.W. A critical review on designs and applications of microalgae-based photobioreactors for pollutants treatment. Sci. Total. Environ. 2019, 651, 1549-1568. [CrossRef]

10. Judd, S.; Broeke, L.J.V.D.; Shurair, M.; Kuti, Y.; Znad, H. Algal remediation of $\mathrm{CO}_{2}$ and nutrient discharges: A review. Water Res. 2015, 87, 356-366. [CrossRef]

11. Cuellar-Bermudez, S.P.; Aleman-Nava, G.S.; Chandra, R.; Garcia-Perez, J.S.; Contreras-Angulo, J.R.; Markou, G.; Muylaert, K.; Rittmann, B.E.; Parra-Saldivar, R. Nutrients utilization and contaminants removal. A review of two approaches of algae and cyanobacteria in wastewater. Algal Res. 2017, 24, 438-449. [CrossRef]

12. Tolboom, S.N.; Carrillo-Nieves, D.; Rostro-Alanis, M.D.J.; Quiroz, R.D.L.C.; Barceló, D.; Iqbal, H.M.; Parra-Saldivar, R. Algal-based removal strategies for hazardous contaminants from the environment-A review. Sci. Total. Environ. 2019, 665, 358-366. [CrossRef] [PubMed]

13. Wilkinson, J.; Hooda, P.S.; Barker, J.; Barton, S.; Swinden, J. Occurrence, fate and transformation of emerging contaminants in water: An overarching review of the field. Environ. Pollut. 2017, 231, 954-970. [CrossRef] [PubMed] 
14. Bergheim, M.; Gminski, R.; Spangenberg, B.; Debiak, M.; Bürkle, A.; Mersch-Sundermann, V.; Kümmerer, K.; Gieré, R. Recalcitrant pharmaceuticals in the aquatic environment: a comparative screening study of their occurrence, formation of phototransformation products and their in vitro toxicity. Environ. Chem. 2014, 11, 431-444. [CrossRef]

15. Lai, K.M.; Scrimshaw, M.D.; Lester, J.N. Biotransformation and Bioconcentration of Steroid Estrogens by Chlorella vulgaris. Appl. Environ. Microbiol. 2002, 68, 859-864. [CrossRef]

16. Peng, F.-Q.; Ying, G.-G.; Yang, B.; Liu, S.; Lai, H.-J.; Liu, Y.-S.; Chen, Z.-F.; Zhou, G.-J. Biotransformation of progesterone and norgestrel by two freshwater microalgae (Scenedesmus obliquus and Chlorella pyrenoidosa): Transformation kinetics and products identification. Chemosphere 2014, 95, 581-588. [CrossRef]

17. Xiong, J.-Q.; Kim, S.-J.; Kurade, M.B.; Govindwar, S.; Abou-Shanab, R.A.; Kim, J.-R.; Roh, H.-S.; Khan, M.A.; Jeon, B.-H. Combined effects of sulfamethazine and sulfamethoxazole on a freshwater microalga, Scenedesmus obliquus: Toxicity, biodegradation, and metabolic fate. J. Hazard. Mater. 2019, 370, 138-146. [CrossRef] [PubMed]

18. Stadler, L.B.; Ernstoff, A.S.; Aga, D.S.; Love, N.G. Micropollutant Fate in Wastewater Treatment: Redefining "Removal". Environ. Sci. Technol. 2012, 46, 10485-10486. [CrossRef]

19. De Laurentiis, E.; Prasse, C.; Ternes, T.A.; Minella, M.; Maurino, V.; Minero, C.; Sarakha, M.; Brigante, M.; Vione, D. Assessing the photochemical transformation pathways of acetaminophen relevant to surface waters: Transformation kinetics, intermediates, and modelling. Water Res. 2014, 53, 235-248. [CrossRef]

20. Caballero, M.V.; Candiracci, M. Zebrafish as screening model for detecting toxicity and drugs efficacy. J. Unexplored Med. Data 2018, 3, 1-14. [CrossRef]

21. Carlsson, G.; Patring, J.; Kreuger, J.; Norrgren, L.; Oskarsson, A. Toxicity of 15 veterinary pharmaceuticals in zebrafish (Danio rerio) embryos. Aquat. Toxicol. 2013, 126, 30-41. [CrossRef]

22. Dai, Y.J.; Jia, Y.F.; Chen, N.; Bian, W.P.; Li, Q.K.; Ma, Y.B.; Chen, Y.L.; Pei, D.S. Zebrafish as a model system to study toxicology. Environ. Toxicol. Chem. 2014, 33, 11-17. [CrossRef] [PubMed]

23. Torres, T.; Cunha, I.; Martins, R.; Santos, M.M. Screening the Toxicity of Selected Personal Care Products Using Embryo Bioassays: 4-MBC, Propylparaben and Triclocarban. Int. J. Mol. Sci. 2016, 17, 1762. [CrossRef] [PubMed]

24. Soares, J.; Coimbra, A.; Reis-Henriques, M.; Monteiro, N.; Vieira, M.; Oliveira, J.; Guedes-Dias, P.; Fontaínhas-Fernandes, A.; Parra, S.S.; Carvalho, A.P.; et al. Disruption of zebrafish (Danio rerio) embryonic development after full life-cycle parental exposure to low levels of ethinylestradiol. Aquat. Toxicol. 2009, 95, 330-338. [CrossRef] [PubMed]

25. Ribeiro, S.; Torres, T.; Martins, R.; Santos, M.M. Toxicity screening of Diclofenac, Propranolol, Sertraline and Simvastatin using Danio rerio and Paracentrotus lividus embryo bioassays. Ecotoxicol. Environ. Saf. 2015, 114, 67-74. [CrossRef] [PubMed]

26. Mann, J.E.; Myers, J. On pigments, growth, and photosynthesis of phaeodactylum tricornutum. J. Phycol. 1968, 4, 349-355. [CrossRef] [PubMed]

27. OECD. OECD Guidelines for the Testing of Chemicals; Test No. 236: Fish Embryo Acute Toxicity (FET) Test; OECD Publishing: Paris, France, 2013. Available online: https://read.oecd-ilibrary.org/environment/test-no236-fish-embryo-acute-toxicity-fet-test_9789264203709-en\#page1 (accessed on 12 September 2019).

28. Kimmel, C.B.; Ballard, W.W.; Kimmel, S.R.; Ullmann, B.; Schilling, T.F. Stages of embryonic development of the zebrafish. Dev. Dyn. 1995, 203, 253-310. [CrossRef] [PubMed]

29. Escapa, C.; Coimbra, R.; Paniagua, S.; García, A.; Otero, M.; Coimbra, R. Nutrients and pharmaceuticals removal from wastewater by culture and harvesting of Chlorella sorokiniana. Bioresour. Technol. 2015, 185, 276-284. [CrossRef]

30. Nogueira, A.F.; Pinto, G.; Correia, B.; Nunes, B. Embryonic development, locomotor behavior, biochemical, and epigenetic effects of the pharmaceutical drugs paracetamol and ciprofloxacin in larvae and embryos of Danio rerio when exposed to environmental realistic levels of both drugs. Environ. Toxicol. 2019, in press. [CrossRef]

31. Xia, L.; Zheng, L.; Zhou, J.L. Effects of ibuprofen, diclofenac and paracetamol on hatch and motor behavior in developing zebrafish (Danio rerio). Chemosphere 2017, 182, 416-425. [CrossRef]

32. Pandya, M.; Patel, D.; Rana, J.; Patel, M.; Khan, N. Hepatotoxicity by Acetaminophen and Amiodarone in Zebrafish Embryos. J. Young Pharm. 2016, 8, 50-52. [CrossRef] 
33. Peng, H.-C.; Wang, Y.-H.; Wen, C.-C.; Wang, W.-H.; Cheng, C.-C.; Chen, Y.-H. Nephrotoxicity assessments of acetaminophen during zebrafish embryogenesis. Comp. Biochem. Physiol. Part C: Toxicol. Pharmacol. 2010, 151, 480-486. [CrossRef] [PubMed]

34. David, A.; Pancharatna, K. Effects of acetaminophen (paracetamol) in the embryonic development of zebrafish, Danio rerio. J. Appl. Toxicol. 2009, 29, 597-602. [CrossRef] [PubMed]

35. Escapa, C.; Coimbra, R.; Paniagua, S.; García, A.; Otero, M. Paracetamol and salicylic acid removal from contaminated water by microalgae. J. Environ. Manag. 2017, 203, 799-806. [CrossRef] [PubMed]

36. Escapa, C.; Coimbra, R.; Paniagua, S.; García, A.; Otero, M. Comparative assessment of diclofenac removal from water by different microalgae strains. Algal Res. 2016, 18, 127-134. [CrossRef]

37. Ramos, A.M.; Otero, M.; Rodrigues, A.E. Recovery of Vitamin B12 and cephalosporin-C from aqueous solutions by adsorption on non-ionic polymeric adsorbents. Sep. Purif. Technol. 2004, 38, 85-98. [CrossRef]

38. Zhou, C.; Zhou, Q.; Zhang, X. Transformation of acetaminophen in natural surface water and the change of aquatic microbes. Water Res. 2019, 148, 133-141. [CrossRef] [PubMed]

39. Escapa, C.; Torres, T.; Neuparth, T.; Coimbra, R.N.; García, A.I.; Santos, M.M.; Otero, M. Zebrafish embryo bioassays for a comprehensive evaluation of microalgae efficiency in the removal of diclofenac from water. Sci. Total. Environ. 2018, 640, 1024-1033. [CrossRef]

40. Villar-Navarro, E.; Baena-Nogueras, R.M.; Paniw, M.; Perales, J.A.; Lara-Martin, P.A. Removal of pharmaceuticals in urban wastewater: High rate algae pond (HRAP) based technologies as an alternative to activated sludge based processes. Water Res. 2018, 139, 19-29. [CrossRef]

41. Ali, M.E.; El-Aty, A.M.A.; Badawy, M.I.; Ali, R.K. Removal of pharmaceutical pollutants from synthetic wastewater using chemically modified biomass of green alga Scenedesmus obliquus. Ecotoxicol. Environ. Saf. 2018, 151, 144-152. [CrossRef]

42. Czech, B.; Jośko, I.; Oleszczuk, P. Ecotoxicological evaluation of selected pharmaceuticals to Vibrio fischeri and Daphnia magna before and after photooxidation process. Ecotoxicol. Environ. Saf. 2014, 104, 247-253. [CrossRef]

43. Le, T.X.H.; Van Nguyen, T.; Yacouba, Z.A.; Zoungrana, L.; Avril, F.; Nguyen, D.L.; Petit, E.; Mendret, J.; Bonniol, V.; Bechelany, M.; et al. Correlation between degradation pathway and toxicity of acetaminophen and its by-products by using the electro-Fenton process in aqueous media. Chemosphere 2017, 172, 1-9. [CrossRef] [PubMed]

44. Xiong, J.-Q.; Kurade, M.B.; Jeon, B.-H. Ecotoxicological effects of enrofloxacin and its removal by monoculture of microalgal species and their consortium. Environ. Pollut. 2017, 226, 486-493. [CrossRef] [PubMed]

45. Semple, K.T.; Cain, R.B.; Schmidt, S. Biodegradation of aromatic compounds by microalgae. FEMS Microbiol. Lett. 1999, 170, 291-300. [CrossRef]

(C) 2019 by the authors. Licensee MDPI, Basel, Switzerland. This article is an open access article distributed under the terms and conditions of the Creative Commons Attribution (CC BY) license (http://creativecommons.org/licenses/by/4.0/). 